\title{
Mutations that affect meiosis in male mice influence the dynamics of the mid-preleptotene and bouquet stages
}

\author{
B. Liebe ${ }^{a, 1}$, G. Petukhova ${ }^{b}$, M. Barchic ${ }^{\text {c }}$ M. Bellani ${ }^{b}$, H. Braselmann $^{d}$, T. Nakano ${ }^{e}$, \\ T.K. Pandita ${ }^{f}$, M. Jasin ${ }^{c}$, A. Fornace ${ }^{g}$, M.L. Meistrich ${ }^{h}$, W.M. Baarends ${ }^{i}$, J. Schimenti ${ }^{j}$, \\ T. de Lange ${ }^{k}$, S. Keeney ${ }^{c}$, R.D. Camerini-Otero ${ }^{b}$, H. Scherthan $^{a, l, *}$
}

${ }^{a}$ Max-Planck-Inst. for Molecular Genetics, Ihnestr. 73, D-14195 Berlin, Germany

${ }^{\mathrm{b}}$ Genetics and Biochemistry Branch, NIDDK, National Inst. of Health, Bethesda, MD 20892, USA

${ }^{c}$ Molecular Biology Program, Memorial Sloan-Kettering Cancer Center, New York, NY 10021, USA

${ }^{\mathrm{d} G S F-F o r s c h u n g s z e n t r u m ~ f u ̈ r ~ U m w e l t ~ u n d ~ G e s u n d h e i t ~ G m b H, ~ I n s t i t u t ~ f u ̈ r ~ M o l e k u l a r e ~ S t r a h l e n b i o l o g i e, ~ B i o s t a t i s t i c s, ~}$

Neuherberg, D-80937 Munich, Germany

${ }^{\text {e}}$ Department of Mol. Cell Biol., Res. Inst. for Microbial Diseases, Osaka University, Osaka 565-0871, Japan

${ }^{\mathrm{f}}$ Department of Radiation Oncology, Washington Univ. School of Medicine, St. Louis, MO 63108, USA

${ }^{g}$ Gene Resp. Section, Center for Cancer Research, NCI, Bethesda, MD, USA

${ }^{\mathrm{h}}$ University of Texas M. D. Anderson Cancer Center, Houston, TX 77030, USA

${ }^{\mathrm{i}}$ Department of Reprod. and Dev., Erasmus MC, 3000 CA Rotterdam, The Netherlands

${ }^{j}$ Center for Vertebrate Genomics, Dept. of Biomed. Sci., College of Vet. Med., Cornell University, Ithaca, NY 14853, USA

${ }^{k}$ Laboratory for Cell Biology and Genetics, Rockefeller University, New York, NY 10021, USA

${ }^{1}$ Bundeswehr Institute of Radiobiology, Neuherbergstr.11, 80937 Munich, Germany

\section{A R T I C L E I N F O R M A T I O N}

Article Chronology:

Received 2 February 2006

Revised version received

20 July 2006

Accepted 22 July 2006

Available online 2 August 2006

Keywords:

ATM

Bouquet

DSB

Meiosis

Mouse

Recombination

Telomere

Spermatogenesis

\section{A B S T R A C T}

Meiosis pairs and segregates homologous chromosomes and thereby forms haploid germ cells to compensate the genome doubling at fertilization. Homologue pairing in many eukaryotic species depends on formation of DNA double strand breaks (DSBs) during early prophase I when telomeres begin to cluster at the nuclear periphery (bouquet stage). By fluorescence in situ hybridization criteria, we observe that mid-preleptotene and bouquet stage frequencies are altered in male mice deficient for proteins required for recombination, ubiquitin conjugation and telomere length control. The generally low frequencies of midpreleptotene spermatocytes were significantly increased in male mice lacking recombination proteins SPO11, MEI1, MLH1, KU80, ubiquitin conjugating enzyme HR6B, and in mice with only one copy of the telomere length regulator Terf1. The bouquet stage was significantly enriched in $\mathrm{Atm}^{-/-}, \mathrm{Spo11^{-/- }}$, Mei1 ${ }^{\text {m1jcs/m1Jcs }}, \mathrm{Mlh1}^{-/-}, \mathrm{Terf1}^{+/-}$and $\mathrm{HrGb}^{-/-}$ spermatogenesis, but not in mice lacking recombination proteins DMC1 and HOP2, the non-homologous end-joining DNA repair factor KU80 and the ATM downstream effector GADD45a. Mice defective in spermiogenesis (Tnp1 ${ }^{-/}, \mathrm{Gmcl}^{-1-}, \mathrm{Asm}^{-1-}$ ) showed wild-type mid-preleptotene and bouquet frequencies. A low frequency of bouquet spermatocytes in Spo11 $11^{-1} \mathrm{Atm}^{-/-}$spermatogenesis suggests that DSBs contribute to the $\mathrm{Atm}^{-/}$-correlated bouquet stage exit defect. Insignificant changes of bouquet frequencies in mice with defects

\footnotetext{
* Corresponding author. Fax: +49893168 2635.

E-mail address: scherth@web.de (H. Scherthan).

${ }^{1}$ Present address: Eugen-Hertel-Str. 30, D-67653 Kaiserslautern, Germany.
} 
in early stages of DSB repair (Dmc1 $1^{-/}, \mathrm{Hop}^{-/-}$) suggest that there is an ATM-specific influence on bouquet stage duration. Altogether, it appears that several pathways influence telomere dynamics in mammalian meiosis.

(c) 2006 Elsevier Inc. All rights reserved.

\section{Introduction}

Meiosis is a succession of two cell divisions that generates genetically diverse haploid gametes (or spores) to cope with the genome doubling at fertilization. During the extended prophase to the first meiotic division homologous chromosomes (homologues) first pair and then segregate from each other. Subsequently, without an intervening round of DNA replication, the meiosis II division segregates sister chromatids and thereby creates haploid gametes or spores. In the majority of sexually reproducing eukaryotes, homologue pairing starts after premeiotic DNA replication, when the DNA loops of sister chromatids have attached to proteinaceous axial elements (AEs/cores) [1] whose ends firmly attach to the nuclear envelope during leptotene stage [2,3]. During the same stage, meiotic recombination commences with breaks in double stranded DNA (DSBs) that are introduced by the conserved transesterase SPO11 [4-6]. DSBs are processed to create single stranded DNA ends that are instrumental for homology search and recognition in many organisms (for reviews see [7-9]).

Leptotene telomeres move along the nuclear envelope (NE) and accumulate in a limited region of the nuclear periphery (bouquet formation) concomitantly with the onset of homologue pairing at the leptotene/zygotene transition. Bouquet formation is thought to serve as a recombination-independent mechanism for the instigation of homologue interactions by bringing about the close proximity of chromosome ends (for review see, $[10,11])$. Telomere clustering may also contribute to telomere size adjustment that involves the recombination machinery [12]. Telomere function has been found important for recombination and synapsis $[13,14]$. In mammalian species, the duration of the bouquet stage, or chromosome polarization, varies between genders [15-17] suggesting that its duration, like the progress of DSB repair, is subject to surveillance, the nature of which is largely enigmatic.

In prophase I of the male mouse, telomere clustering occurs in a time window limited to the onset of zygotene, which only leaves a few such cells detectable ( $0.5 \%$ of spermatocytes) in testes suspensions $[2,18,19]$. This feature is altered in mice deficient for ATM $[20,21]$, a core element of the DNA damage surveillance machinery responsive to DNA damage by DSBs [22]. Atm ${ }^{-1-}$ mice exhibit disrupted meiosis that relates to defects in DNA repair [23,24]. Atm ${ }^{-/}$males show a dramatic increase in the frequency of bouquet stage spermatocytes among total spermatocytes [19,25], raising the possibility that exit from the bouquet stage is delayed in the absence of this DSB-responsive kinase and /or its signals. Furthermore, normal bouquet exit requires the downstream ATM effector histone H2 variant H2A.X [26], as absence of $\mathrm{H} 2 \mathrm{AX}$ in mice induces, among other defects [27], a significant increase of the frequency of bouquet cells and the extension of telomere clustering into pachytene [18]. Meiotic telomere clustering is also extended, but to a lesser extent, in Sycp $3^{-/-}$ males that lack axial elements and are defective in recombination $[2,28]$. On the other hand, mice deficient in the SMC1 $\beta$ cohesin subunit are so far the only mammalian mutants with defective telomere attachment and bouquet formation [29].

Telomere clustering is also a fleeting event in other species with synaptic meiosis. Increased frequencies of bouquet meiocytes have been observed in meiotic cultures of budding yeast mutants that fail to form DSBs (spo11 $\Delta$; [30]), or have defects in recombinational repair (rad50S, rec8s) [3133]. Similarly, Spo11 mutants of Sordaria undergo extended telomere clustering [34], suggesting that the absence of, or defects in recombination slows bouquet stage exit in these species. In the nematode C. elegans, the phenotype of chk-2 and syp-1 mutants suggests that chromosome polarization is regulated through DNA-damage responsive kinases [35]. In all, it appears that the installation of telomere clustering is independent of induction of recombination but that initiation or progress in DSB repair may in some way contribute to the timely resolution of meiotic telomere clustering $[34,36]$.

In mouse spermatogenesis, there is a peculiar change of nuclear topography at the onset of prophase I that can be visualized by centromere/telomere (tel/cen) FISH co-staining [37]. Such nuclei are characterized by a perinuclear sheet of major satellite DNA and intranuclear telomeres and contain replicated repetitive target sequences. Since it is likely that they have completed premeiotic DNA replication, these have been termed mid-preleptotene spermatocytes (late preleptotene spermatocytes fail to exhibit SYCP3 threads but have perinuclear telomeres and major satellite clusters) [37].

Here, we used male mice with defects in the initiation and progress of recombinational DSB repair, ubiquitin conjugation, in telomere integrity and spermiogenic functions to investigate by molecular cytology whether and how bouquet and mid-preleptotene stage duration responds to these conditions. Specifically, we investigated mice with (i) absence of DSBs and recombination, i.e. Spo11 $11^{-/}$mice [38], or defects in recombination, like Mei1 ${ }^{\mathrm{m} 1 \mathrm{jcs} / \mathrm{m} 1 \mathrm{jcs}}$ (hereafter referred to as Mei1 ${ }^{-/-}$[39]; Dmc1 ${ }^{-/-}[40,41]$; Hop2 $2^{-/-}$[42] and Mlh1 ${ }^{-/-}$mice [43]), (ii) mice that are defective for the non-homologous end joining (NHEJ) repair pathway, i.e. SCID (severe combined immunodeficiency; [44] and Ku80 knockout mice [45]) and (iii) Gadd $45 a^{-/-}$mice that are deficient in the p53-dependent DNA damage response downstream of ATM $[46,47]$. Moreover, we examined mice deficient for ubiquitin conjugating enzyme HR6B that have damaged synaptonemal complexes (SCs) near telomeres and show defects in recombination [48], as well as Terf $1^{+/-}$heterozygous mice that carry one inactivated gene encoding the TERF1 (TRF1) telomere repeat binding factor, as $\mathrm{Terf1}^{-/-}$homozygous mice experience embryonic lethality [49]. For comparison, we also analyzed $\mathrm{Asm}^{-/-}$[50], Gmcl-1/(also know as mgcl-1) [51] and Tnp $1^{-/-}$[95] mice, which all are infertile due to defects in sperm differentiation. 


\section{Materials and methods}

\section{Mice and testicular specimens}

Mouse spermatocytes were obtained from testes of mice of about 4 weeks p.p. to exclude potential differences in the onset of the first meiotic wave. Genotyping was done as described in the references given in Table 2. Animals were anaesthetized and sacrificed by cervical dislocation. Testes were immediately resected and shock-frozen for $5 \mathrm{~min}$ in 2-methyl-butane (Sigma) on dry ice and stored at $-80^{\circ} \mathrm{C}$ until further use [19]. Storage for more than 1 year did not adversely influence the performance of the samples in FISH or IF.

\section{Irradiation}

Mice were subjected to whole-body irradiation in a Nordion Gamma Cell 40 (137-Cs source). Mice received 3 Gy at a dose of 78 rad per minute. The irradiated animals were euthanized $26 \mathrm{~h}$ after treatment and their testes collected as described above.

\section{Testes suspensions and fluorescence in situ hybridization}

Preparation of testis suspensions containing structurally preserved nuclei for fluorescence in situ hybridization (FISH) and spermatocyte spreads, as well as FISH to telomeres and major satellite DNA of mouse pericentromeres were carried out as described [2]. An oligonucleotide specific to the major satellite carrying a $5^{\prime} \mathrm{Cy} 5$ label and 7-mer biotin- $\mathrm{T}_{2} \mathrm{AG}_{3}$ and biotin- $\mathrm{C}_{3} \mathrm{TA}_{2}$ telomere repeat-specific DNA oligonucleotides were obtained from a commercial supplier (Invitrogen) and used as described [52].

\section{Immunofluorescence staining}

The following antibodies were used: a monoclonal antibody against $\gamma$-H2AX (Biomol); an antiserum to testis-specific histone H1t [53], kindly provided by P. Moens (York University, York, ON, Canada); an antiserum to the SC protein SYCP3 [54] was a gift of C. Heyting (Wageningen University, Wageningen, Netherlands). The antisera were used at $1 / 1000$ dilution in PBTG (PBS, 0.05\% Tween 20, 0.2\% bovine serum albumin, $0.1 \%$ gelatin). All antibodies were tested in individual staining reactions for their specificity and performance. Secondary antibodies to the primary ones, conjugated with different fluorochromes were from Dianova [19]. Immunostaining experiments were performed as described previously [2].

\section{Microscopic evaluation}

Microscopic evaluation was done by manually counting the cells in a Zeiss Axioskop I epifluorescence microscope (Carl Zeiss) equipped with a double band pass filter for green and red excitation (Chroma) and 63x and 100x Neofluar lens (C. Zeiss) [2]. Haploid, premeiotic and disrupted nuclei were excluded from the evaluation. All slides were evaluated by the same experienced investigator (B.L.) to minimize individual bias and because this type of analysis showed a high level of reproducibility in his hands. Images were recorded using the ISIS image analysis system (MetaSystems).

\section{Statistics}

For comparison of wild types and mutants, chi square tests were used. The Hochberg-Benjamini's false discovery rate (FDR) procedure [46] was used for adjustment of $p$ values, since this approach is more powerful than the Bonferroni method. Statistical significance was accepted, when the Hochberg-Benjamini-adjusted $p$ value was less than 0.05 . The FDR multiplies the $i$-th smallest $p$ value by a factor $m / i$, where $m$ is the total number of independent significance tests; $m$ was set here to 36 , the total number of genotypes tested for alterations in the two substages of prophase I and assuming that the "fold-increase" values between the two substages are not correlated (not all tests done are listed in Table 2). For example, several outcomes of $p<0.0001$ would be adjusted to $<0.0036,<0.0018$ etc., so that in any case $p<0.005$ is a valid assumption for a highly significant difference. For comparison of the tight bouquet frequencies, we used Poisson confidence intervals of Crow and Gardner [55], because of the low frequencies in the control mice.

\section{Results and discussion}

\section{Mid-preleptotene and bouquet stages are rapidly traversed in wild-type spermatogenesis}

The onset of first meiotic prophase sees a dramatic reorganization of nuclear topology and chromosome structure, which in mammals can be quantitatively monitored by centromere/ telomere (cen/tel) FISH to testicular preparations (Fig. 1), a technique that facilitates the screening of a large number of cells required for bouquet analysis $[2,19]$. The conspicuous clustering of telomeres and pericentric major satellite DNA can be used to monitor the abundance of the bouquet stage (as the percentage of total spermatocytes) in mouse spermatogenesis, where tight clustering of peripheral telomeres only briefly installs at the leptotene/zygotene transition coinciding with the onset of synaptic chromosome pairing [37]. As synapsis progresses in the wild-type telomere clustering becomes more relaxed and has disappeared by the end of zygotene. Below we use the term 'bouquet' to address nuclei with telomeres clustered to one side of the nuclear periphery. This category includes nuclei with tight and more relaxed association of telomeres (Figs. 1C-E).

Entry into prophase I, on the other hand, can be deduced from the frequency (percentage of this substage among total spermatocytes) of so-called 'mid-preleptotene' nuclei that upon cen/tel FISH display a conspicuous layer of major satellite DNA/heterochromatin lining the nuclear envelope, while a subset of telomeres locates in the nuclear interior (Fig. 1B) [37]. It should be noted that our mid-preleptotene category is only detectable by cen/tel FISH and will be a substage of the classic preleptotene stage that follows premeiotic S-phase up to the point where AEs develop (leptonema) [56, 57]. We used the frequency of mid-preleptotene and bouquet stage nuclei, as deduced from the percentage of these cells among total 


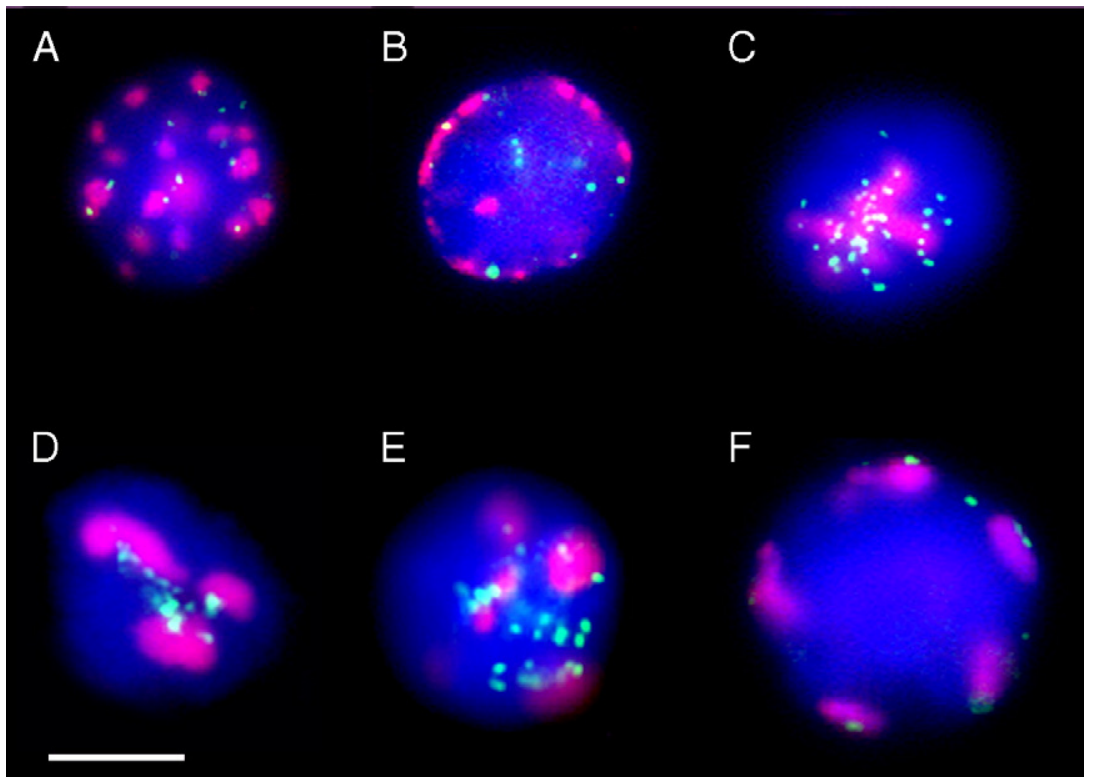

Fig. 1 - Diagnostic cen/tel FISH patterns in mouse spermatocytes. Telomeres ( $\mathrm{T}_{2} \mathrm{AG}_{3}$-FITC, green) and major satellite (Cy5, red) FISH signal distribution aligned according to prophase I progression. (A) Premeiotic nucleus with numerous internal telomere and satellite DNA signals (focal plane at nuclear equator). (B) Mid-preleptotene nucleus with peripheral satellite DNA and internal telomere signals (nuclear equator). (C) Bouquet nucleus at the leptotene/zygotene transition with small telomere signals and satellite DNA tightly clustered at the nuclear top. (D) Bouquet nucleus with most tightly clustered telomere signals (some confluent) and three large major satellite clusters at the nuclear top. Note the irregular shape that is characteristic for this stage. (E) Spermatocyte with more relaxed clustering and larger telomere signals (due to homologue pairing) indicating that it is more progressed in prophase I (likely mid/late zygotene; nuclear top shown). (F) Pachytene nucleus with peripheral telomeres and satellite DNA clusters dispersed about the nuclear equator. Scale bar: $10 \mu \mathrm{m}$. (For interpretation of the references to colour in this figure legend, the reader is referred to the web version of this article.)

spermatocytes, to determine the impact of the disruption of recombinational DSB repair and other chromosome related functions on meiotic centromere and telomere dynamics during earliest prophase I.

First, we determined the percentage of mid-preleptotene and bouquet spermatocytes among total spermatocytes of wild-type mice from different strains by cen/tel FISH to testes suspensions. The use of testes suspensions facilitates FISH scoring of a large number of nuclei directly down the microscope [2], which is required for the study of such a short-lived stage in fixed preparations. In our hands, FISH analysis of testes suspensions proved superior to tissue sections where closely-spaced and overlapping nuclei often complicate the recognition of bouquet stage spermatocytes (H.S., unpublished). Cen/tel FISH analysis of wild-type mice (e.g. C57BL6, 129Sv Jae/ Black Swiss) revealed that testis suspensions on average contain $0.56 \%( \pm 0.42$ SD) midpreleptotene spermatocytes and $0.42 \%( \pm 0.16 \mathrm{SD})$ bouquet spermatocytes among total spermatocytes ( $n=33,631$; Table 1$)$. Tight telomere clustering (Figs. 1C, D), which occurs only at the leptotene/zygotene transition, was observed in $0.07 \%$ $( \pm 0.02 \mathrm{SD})$ of total wild-type spermatocytes $(n=33631)$. Similar frequencies were obtained when mid-preleptotene and bouquet frequencies of testes suspensions of the different mouse strains were considered individually (Table 1). The values obtained also match with earlier cen/tel FISH analysis $[2,37,58]$ and corroborate the view that mid-preleptotene and bouquet stages are short-lived in wild-type males. To exclude potential genotype differences in mutant analyses, we subsequently compared mutant frequencies with the respective isogenic wild-type values (Tables 1 and 2). Statistical evaluation was done using Hochberg-Benjamini's false discovery rate (FDR) procedure for adjustment of $p$ values [59], since this approach is more powerful than the Bonferroni method (see Materials and Methods).

Mice deficient for recombination proteins show increased frequencies of mid-preleptotene and bouquet stage spermatocytes

Next, we analyzed mutants that have impaired fertility and failure to induce or complete recombinational DSB repair (Table 2). Where possible, the percentage of mid-preleptotene and bouquet spermatocytes was determined among at least 4000 successfully hybridized spermatocyte nuclei per genotype that were stained by cen/tel FISH (see Materials and Methods). An increased frequency (\%) relative to the isogenic wild-type frequency was interpreted to indicate an extension of that particular substage $[2,60]$. Previous cen/tel FISH analyses in Lmna ${ }^{-/}$mice, which lack A-type lamins, revealed significantly elevated mid-preleptotene frequencies but wild-type-like bouquet frequencies [58]. On the other hand, Sycp $3^{-/-}$mice, which lack AEs because of deficiency for the SYCP3 (SCP3) AE protein [28], display wild-type midpreleptotene but significantly increased percentage of bouquet spermatocytes [2]. The increases were highly significant 
Table 1 - Frequencies of mid-preleptotene, total and bouquet spermatocytes in different wild-type strains

\begin{tabular}{|c|c|c|c|c|}
\hline WT mice & $n$ & $\%$ mid-preleptotene & $\begin{array}{c}\% \text { bouquet spermatocytes } \\
\text { (\% tight bouquets) }^{\mathrm{a}}\end{array}$ & $\begin{array}{l}\text { Respective mutant } \\
\text { in Table } 2\end{array}$ \\
\hline Spo11 ${ }^{+/+} \mathrm{Atm}^{+/+}$ & 1022 & 0.29 & $0.39(0.19)$ & (1) \\
\hline Hop2 WT & 4187 & 0.45 & $0.19(0.02)$ & (2) \\
\hline Smc1b WT & 2078 & 0.43 & $0.58(0.15)$ & \\
\hline Average C57BL/6 ${ }^{b}$ & 7287 & $0.43 \pm 0.09$ & $0.33 \pm 0.19(0.10)$ & (3) \\
\hline Lmna WT & 1956 & 0.36 & $0.36(0.18)$ & \\
\hline Gadd45a WT & 1002 & 0.50 & $0.60(0.3)$ & (4) \\
\hline Tnp1(3814) WT & 987 & 0.41 & 0.51 (n.d.) & \\
\hline Atm WT & 1010 & 0.69 & 0.30 (n.d.) & \\
\hline Gmcl1 WT & 4264 & 0.38 & 0.28 (n.d.) & (5) \\
\hline Dmc1 WT & 1020 & 0.88 & 0.59 (n.d.) & (6) \\
\hline Average BL6x129/SV C & 10,239 & $0.47 \pm 0.21$ & $0.38 \pm 0.14(0.07)$ & (7) \\
\hline $\mathrm{FVB} / \mathrm{N}$ & 4024 & 0.87 & $0.35(0.10)$ & (8) \\
\hline 129SV/PAS & 4011 & 0.62 & $0.37(0.08)$ & (9) \\
\hline C.B17 & 4061 & 0.76 & $0.30(0.05)$ & (10) \\
\hline 129S6/SvEvTac & 4009 & 0.57 & $0.35(0.07)$ & (11) \\
\hline
\end{tabular}

a Tight bouquets are those whose telomere signals are tightly associated, while total bouquets include telomeres distributed more widely over approximately one third of the NE.

b Average of three mice above; " \pm " in columns 3 and 4 is standard deviation (SD).

c Average of six mice above; n.d., not detected.

using the statistics of this investigation (not shown). Sycp $3^{-/-}$ and Lmna $^{-/-}$mutants both undergo apoptosis in stages after the bouquet stage has resolved, i.e. in early pachytene or equivalent stages $[2,28,58]$. Together, these findings suggest that an increased frequency in one stage does not lead to a similar or inverse effect in the other stage, which may relate

Table 2 - Fold increase in mid-preleptotene and bouquet spermatocytes in spermatogenesis of knockout mice relative to respective isogenic wild type

\begin{tabular}{|c|c|c|c|c|c|c|c|}
\hline $\begin{array}{l}\text { Genotype } \\
\text { (respective isogenic } \\
\text { WT see Table 1) }\end{array}$ & $\begin{array}{l}\text { \% mPL spermatocytes: } \\
\text { (fold increase over }^{\text {isogenic wild type) }}\end{array}$ & $p$ value $^{b}$ & $\begin{array}{c}\text { \% total bouquet } \\
\text { spermatocytes } \\
\text { (fold increase over isogenic } \\
\text { wild type) } \% \% \text { tight bouquets }{ }^{c}\end{array}$ & $p$ value $^{b}$ & H1t-IF ${ }^{d}$ & $n$ & $\begin{array}{c}\text { Mutant } \\
\text { Ref. }\end{array}$ \\
\hline $\mathrm{Atm}^{-/-(11)}$ & $1.34(1.2)$ & $0.62^{e}$ & $9.55\left(13.7^{* *}\right) / 4.33$ & $<0.0036^{\mathrm{e}}$ & - & 4022 & [21] \\
\hline Spo11 $11^{-(1)}$ & $1.96\left(3.3^{*}\right)$ & $0.025^{e}$ & $1.89(2.4) / 0.62$ & $0.096^{\mathrm{e}}$ & - & 4025 & [38] \\
\hline Spo11 $11^{-/(2)}$ & $1.72\left(1.9^{*}\right)$ & $0.020^{\mathrm{e}}$ & $1.95\left(5.1^{* *}\right) / 0.55$ & $<0.0036^{\mathrm{e}}$ & - & 4008 & [64] \\
\hline Spo $11^{-/-} \mathrm{IR}^{(2), \mathrm{f}}$ & $0.95(1)$ & $0.93^{e}$ & $2.81\left(7.4^{* *}\right) / 0.67$ & $<0.0036^{\mathrm{e}}$ & - & 4021 & [64] \\
\hline WT IR ${ }^{(2)}$ & $0.32(0.7)$ & 0.44 & $0.64\left(3.3^{* *}\right) / 0.22$ & 0.0039 & + & 4079 & [64] \\
\hline Spo11 $1^{-/-}$Atm $^{-/-(7)}$ & $0.75(0.8)$ & $0.46^{e}$ & $1.42\left(1.9^{*}\right) / 0.42$ & $0.0066^{e}$ & - & 4022 & [100] \\
\hline Mei1 ${ }^{-/-(3)}$ & $1.51\left(1.8^{*}\right)$ & $0.019^{e}$ & $2.02\left(3.1^{*}\right) / 0.72$ & $0.0072^{e}$ & - & 4053 & [39] \\
\hline $\mathrm{Dmc1}^{-1-(6)}$ & $3.24(1.8)$ & $0.089^{e}$ & $1.19(1) / 0.10$ & $0.98^{e}$ & - & 4044 & {$[40]$} \\
\hline Hop $2^{-/-(2)}$ & 1.49 (1.6) & $0.088^{e}$ & $2.27(0.7) /$ n.d. & $0.58^{e}$ & - & 4101 & [42] \\
\hline $\operatorname{Mlh} 1^{-/-(2)}$ & $1.56\left(3.4^{* *}\right)$ & $<0.0036$ & $1.38\left(7.3^{* *}\right) / 0.52$ & $<0.0036$ & + & 4045 & [43] \\
\hline Prkdc $c^{\text {scid/scid (10) }}$ & 1.19 (1.6) & 0.092 & $0.72\left(2.4^{*}\right) / 0.12$ & 0.016 & + & 4021 & [101] \\
\hline $\mathrm{Ku} 80^{-1-(7)}$ & $1.16\left(2.5^{* *}\right)$ & $<0.0036$ & $0.42(1.1) / 0.05$ & 0.83 & + & 4048 & [87] \\
\hline Gadd $45 a^{-/-(4)}$ & $0.87(1.8)$ & 0.33 & $0.32(0.5) / 0.1$ & 0.34 & + & 4029 & [46] \\
\hline Terf1 $1^{+/-(9)}$ & $2.05\left(3.3^{* *}\right)$ & $<0.0036$ & $1.00\left(2.7^{* *}\right) / 0.07$ & $<0.0036$ & + & 4098 & [49] \\
\hline $\mathrm{Hr} \mathrm{b}^{-1-(8)}$ & $1.95\left(2.3^{* *}\right)$ & $<0.0036$ & $1.29\left(3.7^{* *}\right) / 0.27$ & $<0.0036$ & + & 4041 & [48] \\
\hline $\mathrm{Asm}^{-/-(3)}$ & $0.42(1.0)$ & 1 & $0.52(1.6) / 0.22$ & 0.59 & + & 4036 & [94] \\
\hline $\mathrm{Gmcl1}^{-1-(5)}$ & $0.27(0.7)$ & 0.54 & $0.45(1.6) /$ n.d. & 0.35 & + & 4041 & [51] \\
\hline $\operatorname{Tnp} 1^{-/-(7)}$ & $0.52(1.1)$ & 0.80 & $0.35(0.9) / 0.10$ & 0.84 & + & 4027 & [95] \\
\hline
\end{tabular}

Superscript numbers in column 1 refer to the indexed respective wild-type frequencies shown in Table 1.

${ }^{a}$ Increase of mid-preleptotene (mPL) and bouquet spermatocyte frequencies over corresponding isogenic wild-type frequencies (see Table 1).

${ }^{\mathrm{b}} p$ values adjusted according to the Hochberg-Bejamini method (see Materials and methods). n.d., not detected.

c Tight bouquets are those nuclei whose telomere signals are tightly associated, while total bouquets include telomeres distributed more widely over one third of the NE.

${ }^{\mathrm{d}}$ H1t expression as determined by IF to testes suspensions (see Fig. 2).

e $p$ values of the LR-test taking into account a reduction factor of 0.5 for spermatocytes in the rec ${ }^{-}$mutants that are H1t-negative (H1t-IF-) due to a demise of spermatocytes in mid-pachytene (see respective ref.).

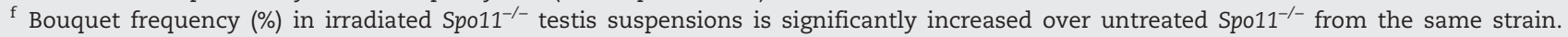
Asterisks mark significant differences according to $\chi^{2}$ statistics: ${ }^{*} p<0.05 ;{ }^{* *} p<0.005$ (see Materials and methods). n.d., not detected. 
to the fact that we analyzed 4-week-old mice that displayed non-synchronous meiosis and showed no arrest in the stages monitored.

Spermatogenesis in other recombination-defective mice is often disrupted after an altered zygotene-like stage (based on AE/SC morphology) with apoptosis usually occurring during stage IV of spermatogenesis that is equivalent to mid pachytene $[24,61]$. The loss of post mid-pachytene spermatocytes in mutants with stage IV apoptosis will inflate the number of earlier substages among the remaining spermatocytes of a testis suspension and relative to wild type, which in turn complicates comparisons between data derived from testes with undisrupted versus arrested spermatogenesis. To compensate for such a deviation in the mutants studied, and because mid-preleptotene and bouquet stage spermatocytes I do not express histone $\mathrm{H} 1 \mathrm{t}$ [19], we investigated for H1t expression by immunofluorescence (IF). H1t is detectable from mid-pachytene (post stage IV) onwards and marks progression of meiotic differentiation beyond this substage $[53,62,63]$. IF staining for histone $\mathrm{H1t}$ immunofluorescence was, in our hands, absent from testis suspensions of the $\mathrm{Atm}^{-/-}, \mathrm{Spo11}^{-/-}$[64], Mei1 ${ }^{-/-}, \mathrm{Dmc1}^{-/-}$and Hop $2^{-/-}$recombination mutants (Fig. 2; Table 2), which agrees with stage IV apoptosis in these mutants [24, 61]. It is of interest that the mice of Baudat et al. [38] express H1t [24], while the Spo11 ${ }^{-/-}$mice of Romanienko and Camerini-Otero [64], failed to show H1t expression in our assay (Table 2). This discrepancy may relate to a progression further into prophase I in the former mice due to strain differences. While differences with the Barchi study cannot be excluded for technical reasons, a difference in telomere cluster resolution between the two strains (see below) also points to a strain-specific prophase I progression in the studied Spo $11^{-1-}$ mice.

Histone H1t-expressing cells make up to $\sim 50 \%$ of spermatocytes in a testes suspension [58] and mid-preleptotene and bouquet stages are found in the H1t-negative spermatocyte fraction [19]. Thus, we compensated for loss of H1t-expressing late prophase I stages in the recombination mutants with spermatogenesis arrest and stage IV apoptosis by adjusting the wild-type mid-preleptotene and bouquet frequencies with that of knockout mice by multiplying the number of wild-type spermatocytes with a correction factor of 0.5 before comparing them to isogenic mutant values (doubling the frequency of the monitored stages yielded the same results, but was not followed for statistical reasons).

SPO11 is required for rapid passage through mid-preleptotene and bouquet stages

Meiotic recombination is initiated by DSBs that are introduced into leptotene DNA by the conserved SPO11 transesterase (for review see $[6,8]$ ). Cen/tel FISH analysis of testes

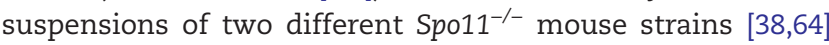
disclosed increased frequencies of mid-preleptotene nuclei in testes suspensions of both Spo11 mutant strains analyzed (Table 2). This increase, with or without correcting for loss of post mid-pachytene spermatocytes, was significant relative to wild type (Table 2) suggesting that the normal transition of the post-replicative mid-preleptotene stage benefits from presence of SPO11.

An increased frequency of bouquet nuclei has been observed in Spo11 mutants of budding yeast [32] and Sordaria [34] that both lack DSBs and recombination, suggesting a link between DSB formation and the exit from meiotic telomere clustering. Previous investigation showed that telomere functions influence synapsis and recombina-

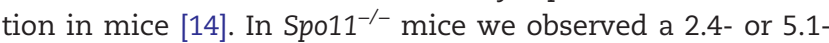
fold increase (depending on strain background) in the frequency of bouquet spermatocytes relative to corrected wild type (Table 2). When comparing the frequencies of spermatocytes with tight telomere clustering (which only occurs at the onset of zygotene), we noted a similar increase in both mutants (Fig. 3). This suggests that duration of the bouquet stage in the mouse also responds to absence of DSBs and/or the SPO11 protein. The latter possibility deserves further investigation, e.g. in a catalytically dead Spo11 mutant.


Fig. 2 - Histone H1t-IF staining (red) on wild-type (A) and Hop $2^{-/}$(B) testicular suspensions. H1t immunofluorescence is only detected in the wild type. The small nuclei represent haploid round spermatids (arrows) and the large nuclei spermatocytes (arrowheads). (B) Hop ${ }^{-/-}$spermatogenesis, like that of all other rec mutants, lacked H1t IF (except for $\mathrm{Mlh1}^{-/}$) and haploid cells. (For interpretation of the references to colour in this figure legend, the reader is referred to the web version of this article.) 


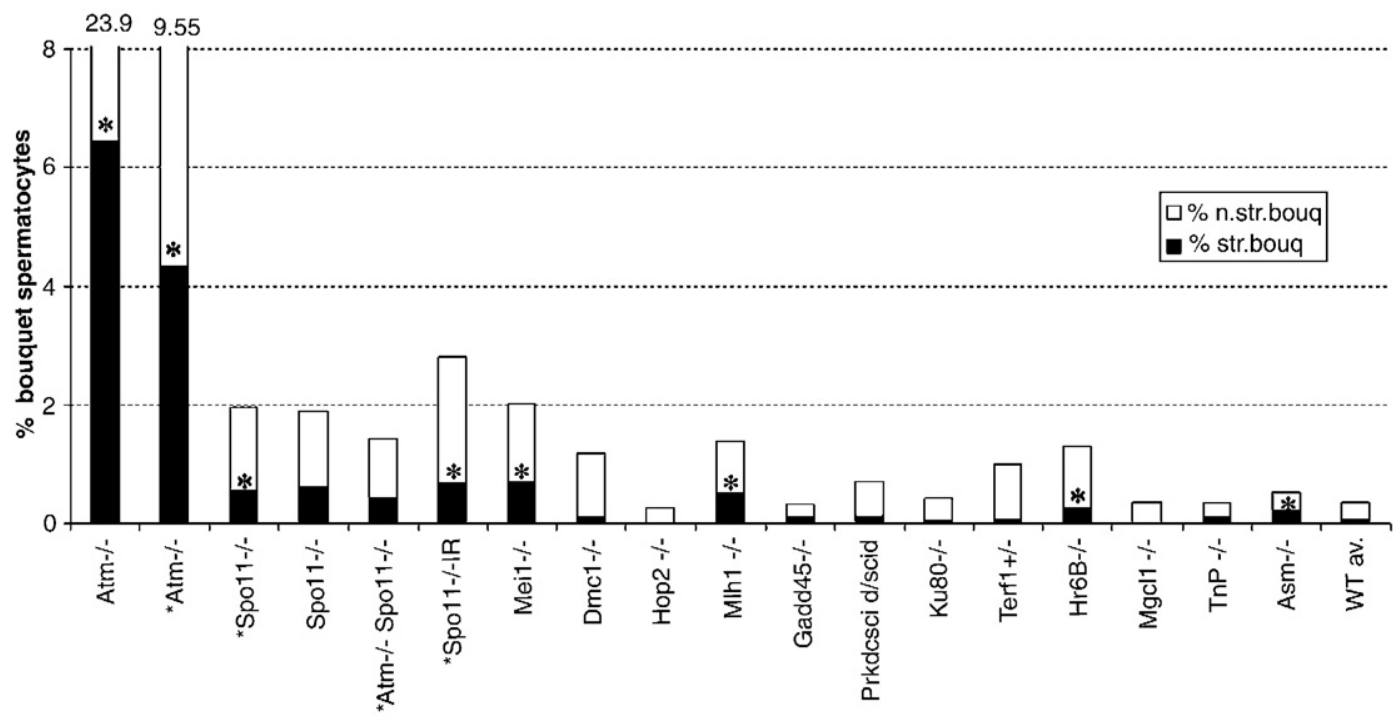

Fig. 3 - Percentage of bouquet spermatocytes with tight (black bars) and more relaxed (white bars) telomere clustering as revealed by cen/tel FISH. The height corresponds to the total frequency among spermatocytes of the indicated mouse genotypes. Asterisks indicate significant differences in tight bouquet frequencies at $p<0.05$ as compared to the respective isogenic wild type (based on chi-square statistics [55]). For comparison, the average wild type value is given to the right (WT av.) and the frequencies of the $\mathrm{Atm}^{-/-}$mice of mixed background [25] are shown to the left. Asterisks in front of the names of the Spo11 mutants denote the same strain background [64]. IR, irradiation.

We also noted that the Spo11 $11^{-1}$ mice of Romanienko and Camerini-Otero [64] displayed a significant 5.1-fold increase over corrected wild type, while the 2.4-fold increase of bouquet spermatocytes in the Spo11 $11^{-/}$mice of Baudat et al. [38] was insignificant, indicating strain-dependent aspects with respect to bouquet stage extension. Slight straindependent differences have also been noted in another study [24]. However, relative to average wild type, both strains showed highly significantly increased bouquet frequencies (not shown). Thus, like in other species, commencement of meiotic telomere clustering and recombination are independent events in mammalian meiosis. Furthermore, the fold increase in Spo11 $11^{-1-}$-induced bouquet stage frequency mirrors the situation in Spo11-mutant meiosis of fungi [32,34], which suggests that DSBs contribute to rapid passage of the bouquet stage in the mouse too.

The relatively moderate increase of bouquet frequencies as compared to Atm or H2ax (now termed H2afx) mutants (Fig. 3 and below; [18]) suggests that DSB formation per se is not a major requirement for exit from the mouse bouquet stage.

DSBs induce prolonged telomere clustering in absence of ATM

Inactivation of the ATM DNA-damage responsive kinase leads to the most dramatic increase in percentage of bouquet spermatocytes with respect to all mouse mutants analyzed for telomere clustering to date, suggesting that ATM is a major factor required for rapid exit from the bouquet stage in the male mouse (reviewed in [60]). Like Spo $11^{-/-}$mice, $\mathrm{Atm}^{-/-}$mice suffer from impaired gametogenesis and undergo stage IV apoptosis but with a more severe phenotype $[23,24]$. To see whether DSBs contribute to bouquet extension in absence of ATM, we analyzed prophase I entry and bouquet stage duration by cen/tel FISH to testis suspensions in $\mathrm{Atm}^{-/}$and $\mathrm{Atm}^{-/-} \mathrm{Spo11^{-/- }}$ mutants. In the strain background studied in this investigation, we noted a $>10$-fold $\mathrm{Atm}^{-/-}$-induced bouquet increase over corrected wild-type values (Table 2). Previous investigation in the C57BL/6X129/Sv mixed background revealed a $\sim 20$ fold increase in bouquet spermatocytes $[19,25]$. However, tight bouquet frequencies between the two strains were similar (3.2\% and 2.2\%; Fig. 3) and highly significantly increased relative to wild type, suggesting that the impact of the Atm mutation is similarly affecting tight bouquet formation in both strains, while there is a difference in the delayed telomere cluster resolution between the two strains, also indicating a strain difference in prophase I progression in this mutant.

To determine the contribution of DSBs to telomere cluster arrest in the $\mathrm{Atm}^{-/-}$condition, we next investigated the double mutant. The $\mathrm{Atm}^{+/-}$Spo11 $11^{-/}$heterozygote was similar to the Spo11 ${ }^{-/-}$single mutant (not shown). The Atm ${ }^{-/-}$Spo11 $1^{-/-}$ double mutant displayed only a 1.9-fold increase of total bouquet spermatocytes relative to corrected wild type (Table 2). This is significantly less than the 13.7-fold and the 5.1-fold increase in the isogenic $\mathrm{Atm}^{-/-}$and $\mathrm{Spo11}^{-/-}$single mutant, respectively. Similar frequencies of tight bouquet spermatocytes were observed in the $\mathrm{Atm}^{-/-} \mathrm{Sp} 011^{-/-}$and $\mathrm{Spo11^{-/- }}$ mutants (Table 2, Fig. 3) indicating that the Spo11 mutation is epistatic to Atm. These results suggest that DSBs are required to elicit the $\mathrm{Atm}^{-/-}$-dependent accumulation of bouquet spermatocytes in male mouse mutants.

Like $\mathrm{Atm}^{-/-}$mice, $\mathrm{Dmc1}^{-/-}$mice show severe gametogenesis defects $[23,24]$. However, Dmc1 $1^{-/-}$spermatogenesis displayed 
wild-type bouquet frequencies, suggesting that ATM contributes to a telomere-specific feature of DSB repair that in particular influences telomere dynamics. Interestingly, in somatic cells, ATM has been shown to directly interact with the telomere repeat binding protein TERF2, which alters the read out of the DNA damage response [65].

\section{Exogenous DSBs extend telomere clustering in mice}

The observations above and previous studies raised the possibility that bouquet stage exit duration could be coupled with progression of DSB repair $[15,32,34]$. If so, we reasoned that delivery of exogenous DSBs should extend the short-lived bouquet stage of male mice. To test for this possibility, we exposed wild-type and Spo11 1 -/ mice that fail to form programmed DSBs, to 3 Gy of $\gamma$-irradiation. This dose, which is well below the lethal dose of $8 \mathrm{~Gy}$ and is tolerated by rodent spermatocytes [66], will deliver approximately 120 DSBs to a mammalian nucleus $[67,68]$. Testes were collected $26 \mathrm{~h}$ postirradiation, which should give ample time either for bouquet exit or extension, given that the minimal time window for telomere clustering in the mouse may comprise $\sim 2 \mathrm{~h}$. The latter being a rough estimate based on a prophase of $336 \mathrm{~h}$ [69] and a mean wild-type bouquet frequency of $0.5 \%$ of total spermatocytes (Table 1). More accurate timing, however, will require further analysis.

Cen/tel FISH to testes suspensions from $\gamma$-irradiated wildtype and $5 p 011^{-/-}$testes disclosed a highly significant increase of the percentage of bouquet stage spermatocytes relative to non-irradiated isogenic Spo $11^{-/-}$or $\mathrm{Spo} 11^{+/+}$mice, while the percentage of mid-preleptotene frequencies was similar (Table 2). Comparing the frequencies of bouquet nuclei with tight telomere clustering revealed closely matching values in irradiated and non-irradiated mice, while the former contained significantly more nuclei with relaxed telomere clustering. This indicates that the time spent in the later phase of the bouquet stage is extended by exogenous DSBs, being consistent with a timely entry but delayed exit from telomere clustering. Moreover, we observed partially improved synapsis and substantial histone H2AX phosphorylation in the $\gamma$-irradiated $S p 011^{-/-}$spermatocytes (Fig. 4), which suggests that exogenous DSBs can at least partially ameliorate prophase I defects of the Spo11 mutation, which is reminiscent of the situation induced by treatment of Spo11 $11^{-/}$ mice with the DSB-seeding drug Cisplatin [64].

Our observations indicate that the delivery of unscheduled, exogenous DSBs, and possibly their repair, is capable to significantly extend bouquet stage duration in spermatogenesis of the male mouse. Alternatively, there is the possibility that irradiation may have caused a general extension of prophase I substages; however, we consider this possibility unlikely, since we observed similar mid-preleptotene frequencies and tight bouquet frequencies in irradiated and nonirradiated testes of wild-type and Spo $11^{-/-}$mice (Table 2, Fig. 3). Furthermore, at the dose applied rodent spermatocytes efficiently repair irradiation-induced DSBs and do not undergo apoptosis $[66,70,71]$.

In contrast to the situation in the mouse testis, irradiation of Sordaria spo11 mutants induced a reduction of the mutation-dependent high bouquet frequencies [34], which indicates a difference to the mammalian situation, which could relate to differences in prophase I duration and a high steady state level of bouquet frequency in Sordaria (5-10\%, [34]), as compared the $\sim 0.4 \%$ of wild-type mouse spermatogenesis (this investigation). In the mouse, the DSB-induced increase of bouquet spermatocyte frequencies is interpreted as a prolonged maintenance of the bouquet stage when exogenous DSBs are seeded into spermatocytes by irradiation, which is likely to induce an additional requirement for time for their processing. In Sordaria, DSB repair proceeds much faster and thus such requirements may not be readily evident. Maintenance of the bouquet stage may also protect chromosomes when these harbor DSBs in a stage that sees vigorous nuclear motility [33,72].

\section{Bouquet stage duration only responds to certain steps in recombination}

To see whether defective DSB repair processing impacts on bouquet stage duration, we investigated mid-preleptotene and bouquet stage frequencies in knockout mice with defects at different steps in recombinational DNA repair.

Mei1 is a gene required for completion of meiosis in both genders of the mouse [39]. Similar to $\mathrm{Spo11^{-/ }}$ mice, spermatocytes of the $\mathrm{Mei1}^{-/-}$mouse cannot form DSBs, are defective in recombination and synapsis, and arrest during an extended zygotene-like stage [73]. Spermatocytes of $\mathrm{Dmcl}^{-1-}$ mice form DSBs but are defective in their processing, display residual synapsis and undergo apoptotic arrest after an aberrant zygotene-like stage during stage IV of spermatogenesis [40].

The MLH1 mismatch repair protein, on the other hand, forms foci at the sites that correspond in number and position to location of crossovers $[43,74,75]$. Both female and male $M l h 1^{-/-}$mice are infertile due to a failure to form reciprocal crossovers and normal spindles at the meiotic division, leading to cell death in the metaphase I stage $[43,76]$. GADD45a is a protein downstream of ATM that is required for maintenance of genome stability $[47,77]$.

Cen/tel FISH to testes suspensions of the mice described above revealed that $\mathrm{Mei1^{-/ }}$ and $\mathrm{Mlh} 1^{-/-}$mice both display significantly increased mid-preleptotene and bouquet frequencies, while $\mathrm{Dmc1}^{-/-}$, Hop $2^{-/-}$and Gadd45 $5^{-/-}$mice are similar to wild type (Table 2, Fig. 3). Mei1 $^{-/-}$mice display similar defects in meiosis like Spo11 ${ }^{-/}$mice $[73,78]$, which extended also tour analysis as we observed similarly increased frequencies of bouquet spermatocytes, both tight and more relaxed ones (Table 2, Fig. 3).

Mlh1 $1^{-/}$mice displayed significantly increased mid-preleptotene and bouquet stage frequencies among total spermatocytes relative to wild type (Table 2, Fig. 3), which is the case with and without correcting for apoptotic events (not shown). As $\mathrm{Mlh}^{-/-}$cells die in metaphase I, and we only analyzed prophase I spermatocytes in our assay, we consider a correction for the obtained MLH1 frequencies as not necessary for the cen/tel-FISH assay. Absence of mismatch repair function of MLH1 has been shown to cause faulty S-phase checkpoint control [79]. Such a defect in premeiotic S-phase may lead to carry-over of DNA lesions, which could underlie the delayed passage through 


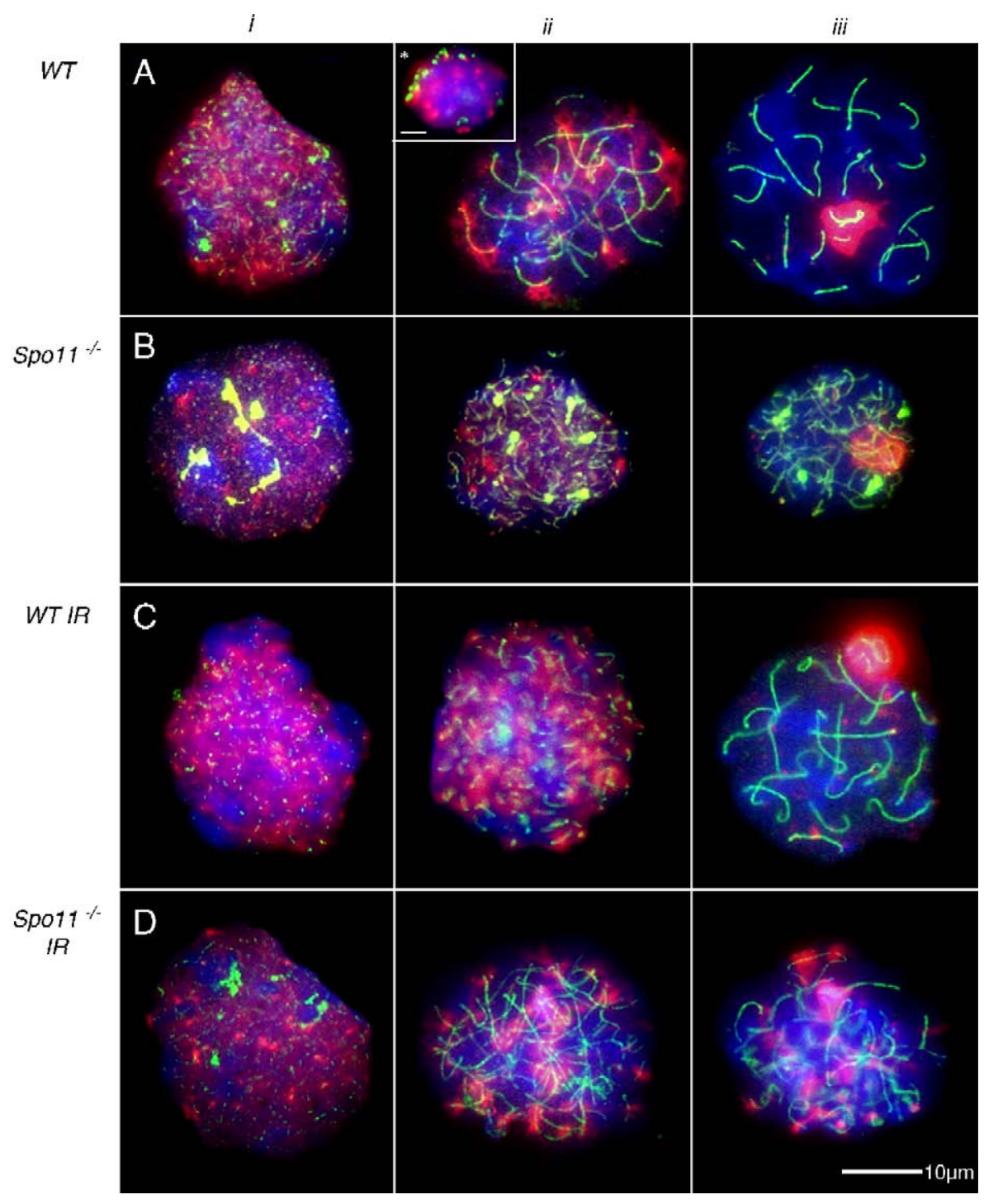

Fig. 4 - Immunofluorescent staining for $\gamma$-H2AX (red) and SYCP3 (green) in spread wild type (WT), Spo11 ${ }^{/-}$, irradiated wild type (WT IR) and irradiated $S p 011^{-/}\left(S p o 11^{-/-}\right.$IR) spermatocytes. $\left(A_{i}\right)$ WT leptotene spermatocyte with weak SYCP3 staining and strong overall $\boldsymbol{\gamma}$-H2AX staining. $\left(A_{\mathrm{ii}}\right)$ WT early zygotene spermatocyte with large patches of $\boldsymbol{\gamma}$-H2AX staining and SYCP3 threads. $\boldsymbol{\gamma}$-H2AX patches persist at some SCs. The inset shows a non-spread bouquet spermatocyte at the nuclear equator with telomeres (green) clustered to the upper right (asterisk) and large patches of $\gamma \mathrm{H} 2 \mathrm{AX}$. Scale bar: $5 \mu \mathrm{m}$. ( $\left(\mathrm{A}_{\mathrm{iii}}\right) \mathrm{WT}$ pachytene spermatocyte with fully formed SCs and $\boldsymbol{\gamma}$-H2AX staining restricted to the XY body (bright red patch). $\left(B_{\mathrm{i}}\right)$ Spo11 ${ }^{-/-}$leptotene nucleus showing some small $\gamma$-H2AX foci, SYCP3 clusters and short axial elements. $\left(B_{i i}\right)$ Early zygotene $S p 011^{-/-}$nucleus with a few small $\gamma-\mathrm{H} 2 \mathrm{AX}$ foci and long unpaired SYCP3-positive axial elements and clusters. $\left(B_{i i i}\right)$ Advanced zygotene Spo11 ${ }^{-/}$nucleus showing unpaired AEs persistent SYCP3 clusters and one large $\boldsymbol{\gamma}$-H2AX patch (see [24] for details). ( $C_{i}$ ) Irradiated leptotene WT spermatocyte showing the same $\boldsymbol{\gamma}$-H2AX and SYCP3 pattern as non-irradiated leptotene spermatocytes. $\left(C_{i i}\right)$ Irradiated early zygotene WT spermatocyte with overall patchy $\gamma$-H2AX staining and SYCP3 threads. $\left(C_{i i i}\right)$ Irradiated WT pachytene spermatocyte with $\gamma$-H2AX staining of the XY body and some additional small radiation-induced $\gamma$-H2AX foci. (D) $\gamma$-irradiated Spo11 ${ }^{-/-}$spermatocytes. $\left(D_{i}\right)$ Leptotene $S p 011^{-/-}$nucleus with several distinct $\gamma$-H2AX foci, SYCP3 AEs and a few SYCP3 patches. ( $\left.D_{\mathrm{ii}}\right)$ Irradiated early zygotene $S p 011^{-/-}$nucleus with several distinct $\gamma$-H2AX patches and SYCP3 threads reminiscent of wild-type zygotene patterns. $\left(D_{\text {iii }}\right)$ Irradiated zygotene-like $S p 011^{-/-}$spermatocyte showing advanced synapsis and large $\gamma-\mathrm{H} 2 \mathrm{AX}$ patches. Note the absence of SYCP3 patches and increase of nucleoid diameter in the irradiated zygotene Spo11 ${ }^{-/-}$spermatocytes. Scale bar: $10 \mu \mathrm{m}$.

the mid-preleptotene stage. Alternatively/additionally, some yet unknown requirement for MLH1 may contribute to the observed defect. In this respect, it is noteworthy that MLH1 has been localized to pericentric heterochromatin of meiotic chromosomes in a Pms2 ${ }^{-/-}$background [80]. Heterochromatin undergoes a dynamic redistribution during mid-prelep- 
tonema [37]. The increase in $\mathrm{Mlh1}^{-/-}$bouquet frequencies, on the other hand, makes it attractive to speculate that the crossover pathway is linked to bouquet exit.

Interestingly, we observed that DMC1, HOP2 and GADD45a are dispensable for telomere cluster resolution as the respective mutants show wild-type-like frequencies (Table 2), with the statistical differences being nonsignificant using the isogenic or averaged wild-type frequencies. Particularly the wild-type bouquet frequency of $\mathrm{Dmcl}^{-/-}$mice distinguishes them from $\mathrm{Atm}^{-/}$mice that otherwise show similarly severe gametogenesis defects $[23,24]$. The low bouquet frequency observed in the Hop2 mutant could indicate problems in formation of the telomere cluster, but conclusive evidence into this direction requires the evaluation of larger numbers of spermatocytes. In any case, our observations suggest that the Dmc1 and Hop2 mutants may fail to set the condition/s that couple telomere dynamics to recombinational DNA repair. Still, this and previous investigations revealed that DSBs in combination with ATM or H2AX deficiency dramatically alter bouquet stage duration [18,25], while delayed bouquet stage exit was much less pronounced in presence of SPO11, MEI1 and MLH1 deficiencies (Table 2), suggesting that the major pathway regulating bouquet exit involves ATM and chromatin factors like histone H2AX. Finally, the possibility cannot be excluded that the baseline increase seen in Spo11 and Mei1 mutants (no DSBs and recombination) might have other causes than disturbed (signaling of) meiotic recombination.

Defects in non-homologous end joining repair pathway affect early prophase I substages

Non-homologous end joining DNA repair (NHEJ) depends on DNA-PK and the KU70/KU80 heterodimer (reviewed in [81]). NHEJ has been shown to have a protective role at somatic telomeres [82,83]. In yeast, scKu80 has been implied in tethering telomeres to the periphery of vegetative nuclei [84]. SCID mice (Prkdc ${ }^{\text {scid/scid }}$ ) carry a mutation in the catalytic subunit of DNA-dependent protein kinase (DNA-PKCS) and are subfertile [85] with a fraction of spermatocytes undergoing apoptosis at stage IV [86]. Cen/tel FISH to Prkdc scid/scid testes suspensions revealed a significantly increased bouquet frequency (Table 2) but an insignificant increase in tight bouquet frequency (Fig. 3). Since the significance of total bouquet increase is at the confidence limit and applying correction for spermatocyte loss above 0.25 removes this significance, we conclude that the exit from telomere clustering is only mildly, if at all, affected by absence of DNA-PKcs function.

$\mathrm{Ku} 80^{-/-}$mice [45], on the other hand, which show a more severe phenotype than SCID mice [71,87], were found to display highly significantly increased mid-preleptotene but normal bouquet frequencies (Table 2). The increased midpreleptotene levels observed in $\mathrm{Ku} 8 \mathrm{O}^{-/-}$mice may relate to carry-over of replication-associated DNA damage from premeiotic cells (spermatogonia; see [71]) due to NHEJ repair deficiency. In all, it seems that defects in the NHEJ DNA repair pathway only induce mild defects in chromosome dynamics in early prophase I.
HR6B ubiquitin-conjugating protein and TERF1 telomere protein contribute to normal chromosome dynamics in prophase I

HR6B (UBE2B), a ubiquitin-conjugating enzyme, is homologous to yeast RAD6/UBC2 and involved in post replication DNA repair and sporulation in yeast [88]. In the mouse, HR6B is required for male fertility [89], with male $\mathrm{Ube}^{-b^{-/}}$mice (for simplicity called $\mathrm{Hr}_{6} \mathrm{~b}^{-1-}$ hereafter) being infertile due to sperm defects, while spermatocytes show altered chromatin and SC structure near telomeres as well as increased levels of recombination as deduced from MLH1 focus analysis [48]. $\mathrm{Cen} / \mathrm{tel} \mathrm{FISH} \mathrm{to} \mathrm{HrGb}^{-/-}$testes suspensions revealed a highly significant increase in mid-preleptotene bouquet spermatocyte frequencies (Table 2). Both tight and more relaxed telomere cluster frequencies were significantly increased (Fig. 3), suggesting that HR6B ubiquitin-conjugating activity is also involved in promoting progression through midpreleptotene and bouquet stages. Since $\mathrm{Hr}_{6} \mathrm{~b}^{-/-}$spermatocytes are recombination proficient, one possibility is that the

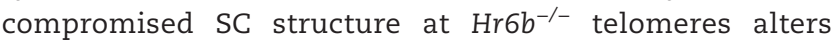
bouquet stage duration. It will hence be interesting to learn about the structure of meiotic $\mathrm{Hr}_{6} \mathrm{~B}^{-/}$telomeres at the EM level. Furthermore, it cannot be ruled out at this stage that there may be a slowed transit through the monitored prophase I stages.

Generation of a mouse that lacks the telomere length regulator protein TERF1 (also known as TRF1) [90] revealed that homozygous Terf1 mutation disrupts embryonic development, suggesting a role for TERF1 in addition to telomere metabolism [49]. TERF1 has been shown to interact with ATM [91] and defective telomeres induce a DNA damage response that involves the ATM pathway [65]. Investigation of $\mathrm{Terf1}^{+/-}$heterozygous mice by cen/tel FISH revealed significantly increased mid-preleptotene and bouquet stage frequencies (Table 2). Particularly bouquet stage spermatocytes with more relaxed telomere clustering were significantly enriched in Terf1 ${ }^{+/-}$mice (Fig. 3) indicating a slowed bouquet exit in these mice. Synapsis and telomere/nuclear envelope attachment was undisturbed (data not shown). The extended mid-preleptotene and bouquet stages in $\mathrm{Terf1}^{+/-}$ mice indicate that TERF1 copy number is important for a wild-type passage through these stages, one possibility being that TERF1 heterozygosity may alter early prophase I progression; dysfunctional telomeres in somatic cells can elicit a cell cycle response [92,93]. Alternatively, an altered protein composition of the meiotic telomere could be involved. Clearly, an issue that deserves more analysis.

\section{Normal prophase I transit in mice with spermiogenic defects}

Finally, we investigated knockout mice with defects in sperm chromatin remodeling or membrane alterations, $\left(\mathrm{Asm}^{-/-}, \mathrm{Gmcl}^{-1^{-/}}\right.$and Tnp1 $\left.{ }^{-/-}\right)$. Asm knockout mice lack the acid sphingomyelinase [94] and are reduced in fertility due to membrane defects in haploid cells [50]. Mice lacking the transition protein 1 (TNP1) are infertile due to a failure in sperm chromatin remodeling $[95,96]$. Gmcl1 (mgcl-1) is the mouse ortholog of the Drosophila germ cell-less (gcl-1) gene. The protein localizes to the nuclear envelope through its 
interaction with LAP2- $\beta$ (lamina-associated polypeptide 2-beta), and $\mathrm{Gmcl}-1^{-/-}$mice display defective sperm chromatin condensation due to faulty expression of transition proteins and protamines [51]. LAP2 $\beta$ is a nuclear envelope-associated protein that could play a role in envelope structure and chromatin attachment. However, cen/tel FISH to spermatocytes of $\mathrm{Asm}^{-/-}, \mathrm{Gmcl}^{-1^{-/-}}$and Tnp1 ${ }^{-/-}$showed normal telomere localization patterns as well as mid-preleptotene and bouquet spermatocyte frequencies (Table 2). Only in $\mathrm{Asm}^{-/}$spermatogenesis there was a significant increase in tight but not of total bouquet frequencies. Altogether, it appears that defects in genes that only affect sperm differentiation seem not to grossly alter entry and progression through early prophase I substages, at least in the mice investigated here.

\section{Conclusions}

Meiotic telomere redistribution in mammals seems to be highly dynamic and the mid-preleptotene and/or bouquet stage is extended in the presence of disruptions in recombination or other functions of meiotic chromosome metabolism. With regard to DSB-repair defects, we observed significantly increased frequencies of mid-preleptotene spermatocytes in male mice lacking SPO11, MEI1, MLH1, KU80 DNA repair proteins, suggesting that the earliest stage of prophase $\mathrm{I}$ is extended in absence of these functions. It could be that these mutations alter the formation of pre-recombination chromatin that is thought to support homologous recombination [97-99].

Significantly elevated bouquet frequencies, on the other hand, were evident in ATM, SPO11 and MLH1-deficient mice, suggesting that bouquet exit is somehow coordinated with DSB repair, like has been suggested for Sordaria [34]. In the mouse it seems that proteins which function in early (SPO11, MEI1, ATM) or late (MLH1) steps of recombinational DSB repair, as well as delivery of exogenous DSBs, can delay telomere cluster exit. However, the absence of other molecules (DMC1, HOP2, NHEJ repair proteins) fails to set the stage for such a response. In comparison to the phenotype of the spo11-Y153F mutant of Sordaria [34] or the rec8 $\Delta$ cohesin mutant of budding yeast [33] the increased frequencies of bouquet stage spermatocytes in the responsive $\mathrm{KO}$ mice are still moderate. The only exception being the $\mathrm{Atm}^{-/-}$mutant that, in combination with physiological DSBs, elicits a major bouquet exit defect. ATM for instance may mediate its instigative role on telomere cluster resolution in part through its downstream effector histone H2AX [18] and possibly through an interaction with the telomere complex component TERF2 [65]. Furthermore, mutations in genes that influence chromosome and telomere metabolism (Hr6b, Terf1) also led to extended bouquet duration. Thus, it appears that several pathways can influence meiotic telomere dynamics in the mouse. It will thus be interesting to further unravel the regulatory puzzle at the mammalian meiotic telomere.

\section{Acknowledgments}

We thank C. Heyting, Wageningen, The Netherlands, and P. Moens, York, CN, for help with the Abs; J. Karlseder, The Salk
Institute for Biol. Studies, La Jolla, CA, for providing Terf1 mice and H.H. Ropers, MPI-MG, Berlin, for support. This work was supported in part by a DFG grant to H.S. (SCHE350/8-4), NIH grants NS34746 and CA10445 to TKP and by fellowships from the American Italian Cancer Foundation and Lalor Foundation to M. Barchi.

\section{R E F E R E N C E S}

[1] P.B. Moens, R.E. Pearlman, H.H. Heng, W. Traut, Chromosome cores and chromatin at meiotic prophase, Curr. Top. Dev. Biol. 37 (1998) 241-262.

[2] B. Liebe, M. Alsheimer, C. Hoog, R. Benavente, H. Scherthan, Telomere attachment, meiotic chromosome condensation, pairing, and bouquet stage duration are modified in spermatocytes lacking axial elements, Mol. Biol. Cell 15 (2004) 827-837.

[3] S.W. Rasmussen, P.B. Holm, Mechanics of meiosis, Hereditas 93 (1980) 187-216.

[4] S. Keeney, C.N. Giroux, N. Kleckner, Meiosis-specific DNA double-strand breaks are catalyzed by Spo11, a member of a widely conserved protein family, Cell 88 (1997) 375-384.

[5] A. Bergerat, B. de Massy, D. Gadelle, P.C. Varoutas, A. Nicolas, P. Forterre, An atypical topoisomerase II from Archaea with implications for meiotic recombination, Nature 386 (1997) 414-417.

[6] S.K. Mahadevaiah, J.M. Turner, F. Baudat, E.P. Rogakou, P. de Boer, J. Blanco-Rodriguez, M. Jasin, S. Keeney, W.M. Bonner, P.S. Burgoyne, Recombinational DNA double-strand breaks in mice precede synapsis, Nat. Genet. 27 (2001) 271-276.

[7] M. Lichten, Meiotic recombination: breaking the genome to save it, Curr. Biol. 11 (2001) R253-R256.

[8] S. Keeney, Mechanism and control of meiotic recombination initiation, Curr. Top. Dev. Biol. 52 (2001) 1-53.

[9] J.L. Gerton, R.S. Hawley, Homologous chromosome interactions in meiosis: diversity amidst conservation, Nat. Rev., Genet. 6 (2005) 477-487.

[10] H. Scherthan, Meiotic telomeres, in: E. Blackburn (Ed.), Telomeres, 2nd ed., CSH Press, Cold Spring Harbor, 2006.

[11] L. Harper, I. Golubovskaya, W.Z. Cande, A bouquet of chromosomes, J. Cell Sci. 117 (2004) 4025-4032.

[12] I. Joseph, D. Jia, A.J. Lustig, Ndj1p-dependent epigenetic resetting of telomere size in yeast meiosis, Curr. Biol. 15 (2005) 231-237.

[13] H.Y. Wu, S.M. Burgess, Ndj1, a telomere-associated protein, promotes meiotic recombination in budding yeast, Mol. Cell. Biol. 26 (2006) 3683-3694.

[14] L. Liu, S. Franco, B. Spyropoulos, P.B. Moens, M.A. Blasco, D.L. Keefe, Irregular telomeres impair meiotic synapsis and recombination in mice, Proc. Natl. Acad. Sci. U. S. A. 101 (2004) 6496-6501.

[15] I. Roig, B. Liebe, J. Egozcue, L. Cabero, M. Garcia, H. Scherthan, Female-specific features of recombinational double-stranded DNA repair in relation to synapsis and telomere dynamics in human oocytes, Chromosoma 113 (2004) 22-33.

[16] C. Pfeifer, H. Scherthan, P.D. Thomsen, Sex-specific telomere redistribution and synapsis initiationin cattle oogenesis, Dev. Biol. 255 (2003) 206-215.

[17] M. Tankimanova, M.A. Hulten, C. Tease, The initiation of homologous chromosome synapsis in mouse fetal oocytes is not directly driven by centromere and telomere clustering in the bouquet, Cytogenet. Genome Res. 105 (2004) 172-181.

[18] O. Fernandez-Capetillo, B. Liebe, H. Scherthan, 
A. Nussenzweig, $\mathrm{H} 2 \mathrm{AX}$ regulates meiotic telomere clustering, J. Cell Biol. 163 (2003) 15-20.

[19] H. Scherthan, M. Jerratsch, S. Dhar, Y.A. Wang, S.P. Goff, T.K. Pandita, Meiotic telomere distribution and Sertoli cell nuclear architecture are altered in Atm- and Atm-p53-deficient mice, Mol. Cell. Biol. 20 (2000) 7773-7783.

[20] Y. Xu, T. Ashley, E.E. Brainerd, R.T. Bronson, M.S. Meyn, D. Baltimore, Targeted disruption of ATM leads to growth retardation, chromosomal fragmentation during meiosis, immune defects, and thymic lymphoma, Genes Dev. 10 (1996) 2411-2422.

[21] C. Barlow, S. Hirotsune, R. Paylor, M. Liyanage, M. Eckhaus, F. Collins, Y. Shiloh, J.N. Crawley, T. Ried, D. Tagle, A. Wynshaw-Boris, Atm-deficient mice: a paradigm of ataxia telangiectasia, Cell 86 (1996) 159-171.

[22] R.T. Abraham, Cell cycle checkpoint signaling through the ATM and ATR kinases, Genes Dev.. 15 (2001) 2177-2196.

[23] M. Di Giacomo, M. Barchi, F. Baudat, W. Edelmann, S. Keeney, M. Jasin, Distinct DNA-damage-dependent and -independent responses drive the loss of oocytes in recombination-defective mouse mutants, Proc. Natl. Acad. Sci. U. S. A. 102 (2005) 737-742.

[24] M. Barchi, S.K. Mahadevaiah, M. Di Giacomo, F. Baudat, D.G. de Rooij, P.S. Burgoyne, M. Jasin, S. Keeney, Surveillance of different recombination defects in mouse spermatocytes yields distinct responses despite elimination at an identical developmental stage, Mol. Cell. Biol. 25 (2005) 7203-7215.

[25] T.K. Pandita, C.H. Westphal, M. Anger, S.G. Sawant, C.R. Geard, R.K. Pandita, H. Scherthan, Atm inactivation results in aberrant telomere clustering during meiotic prophase, Mol. Cell. Biol. 19 (1999) 5096-5105.

[26] E.P. Rogakou, D.R. Pilch, A.H. Orr, V.S. Ivanova, W.M. Bonner, DNA double-stranded breaks induce histone H2AX phosphorylation on serine 139, J. Biol. Chem. 273 (1998) 5858-5868.

[27] A. Celeste, S. Petersen, P.J. Romanienko, O. Fernandez-Capetillo, H.T. Chen, O.A. Sedelnikova, B. Reina-San-Martin, V. Coppola, E. Meffre, M.J. Difilippantonio, C. Redon, D.R. Pilch, A. Olaru, M. Eckhaus, R.D. Camerini-Otero, L. Tessarollo, F. Livak, K. Manova, W.M. Bonner, M.C. Nussenzweig, A. Nussenzweig, Genomic instability in mice lacking histone H2AX, Science 296 (2002) 922-927.

[28] L. Yuan, J.G. Liu, J. Zhao, E. Brundell, B. Daneholt, C. Hoog, The murine SCP3 gene is required for synaptonemal complex assembly, chromosome synapsis, and male fertility, Mol. Cell 5 (2000) 73-83.

[29] E. Revenkova, M. Eijpe, C. Heyting, C.A. Hodges, P.A. Hunt, B. Liebe, H. Scherthan, R. Jessberger, Cohesin SMC1 beta is required for meiotic chromosome dynamics, sister chromatid cohesion and DNA recombination, Nat. Cell Biol. 6 (2004) 555-562.

[30] L. Cao, E. Alani, N. Kleckner, A pathway for generation and processing of double-strand breaks during meiotic recombination in S. cerevisiae, Cell 61 (1990) 1089-1101.

[31] E. Alani, R. Padmore, N. Kleckner, Analysis of wild-type and rad50 mutants of yeast suggests an intimate relationship between meiotic chromosome synapsis and recombination, Cell 61 (1990) 419-436.

[32] E. Trelles-Sticken, J. Loidl, H. Scherthan, Bouquet formation in budding yeast: initiation of recombination is not required for meiotic telomere clustering, J. Cell Sci. 112 (Pt 5) (1999) 651-658.

[33] E. Trelles-Sticken, C. Adelfalk, J. Loidl, H. Scherthan, Meiotic telomere clustering requires actin for its formation and cohesin for its resolution, J. Cell Biol. 170 (2005) 213-223.

[34] A. Storlazzi, S. Tesse, S. Gargano, F. James, N. Kleckner, D. Zickler, Meiotic double-strand breaks at the interface of chromosome movement, chromosome remodeling, and reductional division, Genes Dev.. 17 (2003) 2675-2687.
[35] A.J. MacQueen, M.P. Colaiacovo, K. McDonald, A.M. Villeneuve, Synapsis-dependent and -independent mechanisms stabilize homolog pairing during meiotic prophase in C. elegans, Genes Dev. 16 (2002) 2428-2442.

[36] H. Scherthan, Meiotic telomeres, in: E. Blackburn (Ed.), Telomeres, 2nd ed., CSH Press, Cold Spring Harbor, 2005.

[37] H. Scherthan, S. Weich, H. Schwegler, C. Heyting, M. Harle, $\mathrm{T}$. Cremer, Centromere and telomere movements during early meiotic prophase of mouse and man are associated with the onset of chromosome pairing, J. Cell Biol. 134 (1996) 1109-1125.

[38] F. Baudat, K. Manova, J.P. Yuen, M. Jasin, S. Keeney, Chromosome synapsis defects and sexually dimorphic meiotic progression in mice lacking Spo11, Mol. Cell 6 (2000) 989-998.

[39] B.J. Libby, R. De La Fuente, M.J. O’Brien, K. Wigglesworth, J. Cobb, A. Inselman, S. Eaker, M.A. Handel, J.J. Eppig, J.C. Schimenti, The mouse meiotic mutation mei1 disrupts chromosome synapsis with sexually dimorphic consequences for meiotic progression, Dev. Biol. 242 (2002) 174-187.

[40] D.L. Pittman, J. Cobb, K.J. Schimenti, L.A. Wilson, D.M. Cooper, E. Brignull, M.A. Handel, J.C. Schimenti, Meiotic prophase arrest with failure of chromosome synapsis in mice deficient for Dmc1, a germline-specific RecA homolog, Mol. Cell 1 (1998) 697-705.

[41] K. Yoshida, G. Kondoh, Y. Matsuda, T. Habu, Y. Nishimune, T. Morita, The mouse RecA-like gene Dmc1 is required for homologous chromosome synapsis during meiosis, Mol. Cell 1 (1998) 707-718.

[42] G.V. Petukhova, P.J. Romanienko, R.D. Camerini-Otero, The Hop2 protein has a direct role in promoting interhomolog interactions during mouse meiosis, Dev. Cell 5 (2003) 927-936.

[43] W. Edelmann, P.E. Cohen, M. Kane, K. Lau, B. Morrow, S. Bennett, A. Umar, T. Kunkel, G. Cattoretti, R. Chaganti, J.W. Pollard, R.D. Kolodner, R. Kucherlapati, Meiotic pachytene arrest in MLH1-deficient mice, Cell 85 (1996) 1125-1134.

[44] G.C. Bosma, R.P. Custer, M.J. Bosma, A severe combined immunodeficiency mutation in the mouse, Nature 301 (1983) 527-530.

[45] A. Nussenzweig, C. Chen, V. da Costa Soares, M. Sanchez, K. Sokol, M.C. Nussenzweig, G.C. Li, Requirement for Ku80 in growth and immunoglobulin V(D)J recombination, Nature 382 (1996) 551-555.

[46] M.C. Hollander, M.S. Sheikh, D.V. Bulavin, K. Lundgren, L. Augeri-Henmueller, R. Shehee, T.A. Molinaro, K.E. Kim, E. Tolosa, J.D. Ashwell, M.P. Rosenberg, Q. Zhan, P.M. Fernandez-Salguero, W.F. Morgan, C.X. Deng, A.J. Fornace Jr. Genomic instability in Gadd45a-deficient mice, Nat. Genet. 23 (1999) 176-184.

[47] M.B. Kastan, Q. Zhan, W.S. el-Deiry, F. Carrier, T. Jacks, W.V. Walsh, B.S. Plunkett, B. Vogelstein, A.J.J. Fornace, A mammalian cell cycle checkpoint pathway utilizing $\mathrm{p} 53$ and GADD45 is defective $n$ ataxia-telangiectasia, Cell 71 (1992) 587-597.

[48] W.M. Baarends, E. Wassenaar, J.W. Hoogerbrugge, G. van Cappellen, H.P. Roest, J. Vreeburg, M. Ooms, J.H. Hoeijmakers, J.A. Grootegoed, Loss of HR6B ubiquitin-conjugating activity results in damaged synaptonemal complex structure and increased crossingover frequency during the male meiotic prophase, Mol. Cell. Biol. 23 (2003) 1151-1162.

[49] J. Karlseder, L. Kachatrian, H. Takai, K. Mercer, S. Hingorani, T. Jacks, T. de Lange, Targeted deletion reveals an essential function for the telomere length regulator Trf1, Mol. Cell. Biol. 23 (2003) 6533-6541.

[50] A. Butler, X. He, R.E. Gordon, H.S. Wu, S. Gatt, 
E.H. Schuchman, Reproductive pathology and sperm physiology in acid sphingomyelinase-deficient mice, Am. J. Pathol. 161 (2002) 1061-1075.

[51] T. Kimura, C. Ito, S. Watanabe, T. Takahashi, M. Ikawa, K. Yomogida, Y. Fujita, M. Ikeuchi, N. Asada, K. Matsumiya, A. Okuyama, M. Okabe, K. Toshimori, T. Nakano, Mouse germ cell-less as an essential component for nuclear integrity, Mol. Cell. Biol. 23 (2003) 1304-1315.

[52] H. Scherthan, Detection of chromosome ends by telomere FISH, Methods Mol. Biol. 191 (2002) 13-31.

[53] P.B. Moens, Histones H1 and H4 of surface-spread meiotic chromosomes, Chromosoma 104 (1995) 169-174.

[54] J.H. Lammers, H.H. Offenberg, M. van Aalderen, A.C. Vink, A.J. Dietrich, C. Heyting, The gene encoding a major component of the lateral elements of synaptonemal complexes of the rat is related to X-linked lymphocyte-regulated genes, Mol. Cell. Biol. 14 (1994) 1137-1146.

[55] E.L. Crow, R.S. Gardner, Confidence intervals for the expectation of a poisson variable, Biometrika 46 (1959) 441-453.

[56] E.F. Oakberg, Duration of spermatogenesis in the mouse and timing of stages of the cycle of the seminiferous epithelium, Am. J. Anat. 99 (1956) 507-516.

[57] J.L. Oud, A.H.H. Reutlinger, Chromosome behaviour during early meiotic prophase of mouse spermatocytes, Chromosoma 83 (1981) 395-407.

[58] M. Alsheimer, B. Liebe, L. Sewell, C.L. Stewart, H. Scherthan, R. Benavente, Disruption of spermatogenesis in mice lacking A-type lamins, J. Cell Sci. 117 (2004) 1173-1178.

[59] Y. Benjamini, Y. Hochberg, Controlling the false discovery rate: a practical and powerful approach to multiple testing, J. R. Stat. Soc., B 57 (1995) 289-300.

[60] H. Scherthan, Knockout mice provide novel insights into meiotic chromosome and telomere dynamics, Cytogenet. Genome Res. 103 (2003) 235-244.

[61] D.G. de Rooij, P. de Boer, Specific arrests of spermatogenesis in genetically modified and mutant mice, Cytogenet. Genome Res. 103 (2003) 267-276.

[62] B. Drabent, C. Bode, B. Bramlage, D. Doenecke, Expression of the mouse testicular histone gene H1t during spermatogenesis, Histochem. Cell. Biol. 106 (1996) 247-251.

[63] A. Inselman, S. Eaker, M.A. Handel, Temporal expression of cell cycle-related proteins during spermatogenesis: establishing a timeline for onset of the meiotic divisions, Cytogenet. Genome Res. 103 (2003) 277-284.

[64] P.J. Romanienko, R.D. Camerini-Otero, The mouse Spo11 gene is required for meiotic chromosome synapsis, Mol. Cell 6 (2000) 975-987.

[65] J. Karlseder, K. Hoke, O.K. Mirzoeva, C. Bakkenist, M.B. Kastan, J.H. Petrini, T. Lange Td, The telomeric protein TRF2 binds the ATM kinase and can inhibit the ATM-dependent DNA damage response, PLoS Biol. 2 (2004) E240.

[66] T.P. Coogan, I.Y. Rosenblum, DNA double-strand damage and repair following gamma-irradiation in isolated spermatogenic cells, Mutat. Res. 194 (1988) 183-191.

[67] K. Rothkamm, M. Lobrich, Evidence for a lack of DNA double-strand break repair in human cells exposed to very low x-ray doses, Proc. Natl. Acad. Sci. U. S. A. 100 (2003) 5057-5062.

[68] W.M. Bonner, Low-dose radiation: thresholds, bystander effects, and adaptive responses, Proc. Natl. Acad. Sci. U. S. A. 100 (2003) 4973-4975.

[69] I.D. Adler, Comparison of the duration of spermatogenesis between male rodents and humans, Mutat. Res. 352 (1996) 169-172.

[70] E.F. Oakberg, D.R. L., X-ray sensitivity of primary spermatocytes of the mouse, Int. J. Radiat. Biol. 2 (1960) 196-209.

[71] G. Hamer, H.L. Roepers-Gajadien, A. van Duyn-Goedhart, I.S. Gademan, H.B. Kal, P.P. van Buul, D.G. de Rooij, DNA double-strand breaks and gamma-H2AX signaling in the testis, Biol. Reprod. 68 (2003) 628-634.

[72] M. Parvinen, K.O. Soderstrom, Chromosome rotation and formation of synapsis, Nature 260 (1976) 534-535.

[73] B.J. Libby, L.G. Reinholdt, J.C. Schimenti, Positional cloning and characterization of Mei1, a vertebrate-specific gene required for normal meiotic chromosome synapsis in mice, Proc. Natl. Acad. Sci. U. S. A. 100 (2003) 15706-15711.

[74] E. Marcon, P. Moens, MLH1p and MLH3p localize to precociously induced chiasmata of okadaic-acid-treated mouse spermatocytes, Genetics 165 (2003) 2283-2287.

[75] L. Froenicke, L.K. Anderson, J. Wienberg, T. Ashley, Male mouse recombination maps for each autosome identified by chromosome painting, Am. J. Hum. Genet. 71 (2002) 1353-1368.

[76] L.M. Woods, C.A. Hodges, E. Baart, S.M. Baker, M. Liskay, P.A. Hunt, Chromosomal influence on meiotic spindle assembly: abnormal meiosis I in female Mlh1 mutant mice, J. Cell Biol. 145 (1999) 1395-1406.

[77] M.C. Hollander, I. Alamo, J. Jackman, M.G. Wang, O.W. McBride, A.J. Fornace Jr., Analysis of the mammalian gadd45 gene and its response to DNA damage, J. Biol. Chem. 268 (1993) 24385-24393.

[78] L.G. Reinholdt, J.C. Schimenti, Mei1 is epistatic to Dmc1 during mouse meiosis, Chromosoma 114 (2005) 127-134.

[79] K.D. Brown, A. Rathi, R. Kamath, D.I. Beardsley, Q. Zhan, J.L. Mannino, R. Baskaran, The mismatch repair system is required for S-phase checkpoint activation, Nat. Genet. 33 (2003) 80-84.

[80] N.K. Kolas, A. Svetlanov, M.L. Lenzi, F.P. Macaluso, S.M. Lipkin, R.M. Liskay, J. Greally, W. Edelmann, P.E. Cohen, Localization of MMR proteins on meiotic chromosomes in mice indicates distinct functions during prophase I, J. Cell Biol. 171 (2005) 447-458.

[81] J.A. Downs, S.P. Jackson, A means to a DNA end: the many roles of Ku, Nat. Rev., Mol. Cell Biol. 5 (2004) 367-378.

[82] A. Smogorzewska, J. Karlseder, H. Holtgreve-Grez, A. Jauch, T. de Lange, DNA ligase IV-dependent NHEJ of deprotected mammalian telomeres in G1 and G2, Curr. Biol. 12 (2002) 1635-1644.

[83] F.A. Goytisolo, E. Samper, S. Edmonson, G.E. Taccioli, M.A. Blasco, The absence of the DNA-dependent protein kinase catalytic subunit in mice results in anaphase bridges and in increased telomeric fusions with normal telomere length and G-strand overhang, Mol. Cell. Biol. 21 (2001) 3642-3651.

[84] T. Laroche, S.G. Martin, M. Gotta, H.C. Gorham, F.E. Pryde, E.J. Louis, S.M. Gasser, Mutation of yeast Ku genes disrupts the subnuclear organization of telomeres, Curr. Biol. 8 (1998) 653-656.

[85] T. Blunt, D. Gell, M. Fox, G.E. Taccioli, A.R. Lehmann, S.P. Jackson, P.A. Jeggo, Identification of a nonsense mutation in the carboxyl-terminal region of DNA-dependent protein kinase catalytic subunit in the scid mouse, Proc. Natl. Acad. Sci. U. S. A. 93 (1996) 10285-10290.

[86] G. Hamer, H.L. Roepers-Gajadien, A. van Duyn-Goedhart, I.S. Gademan, H.B. Kal, P.P. van Buul, T. Ashley, D.G. de Rooij, Function of DNA-protein kinase catalytic subunit during the early meiotic prophase without Ku70 and Ku86, Biol. Reprod. 68 (2003) 717-721.

[87] A. Nussenzweig, K. Sokol, P. Burgman, L. Li, G.C. Li, Hypersensitivity of Ku80-deficient cell lines and mice to DNA damage: the effects of ionizing radiation on growth, survival, and development, Proc. Natl. Acad. Sci. U. S. A. 94 (1997) 13588-13593. 
[88] B.A. Montelone, S. Prakash, L. Prakash, Recombination and mutagenesis in rad6 mutants of Saccharomyces cerevisiae: evidence for multiple functions of the RAD6 gene, Mol. Gen. Genet. 184 (1981) 410-415.

[89] H.P. Roest, J. van Klaveren, J. de Wit, C.G. van Gurp, M.H. Koken, M. Vermey, J.H. van Roijen, J.W. Hoogerbrugge, J.T. Vreeburg, W.M. Baarends, D. Bootsma, J.A. Grootegoed, J.H. Hoeijmakers, Inactivation of the HR6B ubiquitin-conjugating DNA repair enzyme in mice causes male sterility associated with chromatin modification, Cell 86 (1996) 799-810.

[90] L. Chong, B. van Steensel, D. Broccoli, H. Erdjument-Bromage, J. Hanish, P. Tempst, T. de Lange, A human telomeric protein, Science 270 (1995) 1663-1667.

[91] S. Kishi, X.Z. Zhou, Y. Ziv, C. Khoo, D.E. Hill, Y. Shiloh, K.P. Lu, Telomeric protein Pin2/TRF1 as an important ATM target in response to double strand DNA breaks, J. Biol. Chem. 276 (2001) 29282-29291.

[92] J.J. Jacobs, T. de Lange, p16INK4a as a second effector of the telomere damage pathway, Cell (2005) 4.

[93] X.Z. Zhou, K. Perrem, K.P. Lu, Role of Pin2/TRF1 in telomere maintenance and cell cycle control, J. Cell. Biochem. 89 (2003) 19-37.

[94] K. Horinouchi, S. Erlich, D.P. Perl, K. Ferlinz, C.L. Bisgaier, K. Sandhoff, R.J. Desnick, C.L. Stewart, E.H. Schuchman, Acid sphingomyelinase deficient mice: a model of types A and B Niemann-Pick disease, Nat. Genet. 10 (1995) 288-293.
[95] Y.E. Yu, Y. Zhang, E. Unni, C.R. Shirley, J.M. Deng, L.D. Russell, M.M. Weil, R.R. Behringer, M.L. Meistrich, Abnormal spermatogenesis and reduced fertility in transition nuclear protein 1-deficient mice, Proc. Natl. Acad. Sci. U. S. A. 97 (2000) 4683-4688.

[96] M.L. Meistrich, B. Mohapatra, C.R. Shirley, M. Zhao, Roles of transition nuclear proteins in spermiogenesis, Chromosoma 111 (2003) 483-488.

[97] M. Eijpe, H. Offenberg, W. Goedecke, C. Heyting, Localisation of RAD50 and MRE11 in spermatocyte nuclei of mouse and rat, Chromosoma 109 (2000) 123-132.

[98] W. Goedecke, M. Eijpe, H.H. Offenberg, M. van Aalderen, C. Heyting, Mre11 and Ku70 interact in somatic cells, but are differentially expressed in early meiosis, Nat. Genet. 23 (1999) 194-198.

[99] K.C. Reddy, A.M. Villeneuve, C. elegans HIM-17 links chromatin modification and competence for initiation of meiotic recombination, Cell 118 (2004) 439-452.

[100] M.A. Bellani, P.J. Romanienko, D.A. Cairatti, R.D. Camerini-Otero, SPO11 is required for sex body formation and Spo11 heterozygosity rescues the prophase arrest of Atm-/- spermatocytes, J. Cell Sci. 118 (2005) 3233-3245.

[101] P.P. van Buul, L. Abramsson-Zetterberg, I.M. Zandman, A. van Duyn-Goedhart, Further characterization of the radiosensitivity of the scid mouse, Int. J. Radiat. Biol. 74 (1998) 35-41. 